\title{
Benefits of the angiotensin II receptor antagonist olmesartan in controlling hypertension and cerebral hemodynamics after stroke
}

\author{
Shuji Matsumoto, Megumi Shimodozono, Ryuji Miyata and Kazumi Kawahira
}

The purpose of this study was to assess the relative benefits of angiotensin II receptor blockers (ARBs) and calcium channel blockers (CCBs) on cerebral hemodynamics and rehabilitation outcome in hypertensive stroke patients. We randomly assigned 35 patients to either the olmesartan $(n=18)$ or amlodipine $(n=17)$ treatment groups for 8 weeks. Changes in cerebral blood flow (CBF) and cerebrovascular reserve capacity (CRC) were quantified using xenon-CT and rehabilitation parameters were also measured. Over $24 \mathrm{~h}$, olmesartan and amlodipine both reduced blood pressure (BP) to similar levels (systolic BP, $-16.1 \pm 2.7 \mathrm{~mm} \mathrm{Hg}$ vs. $-15.7 \pm 3.1$; diastolic BP, $-9.2 \pm 2.9$ vs. $-8.6 \pm 3.3 \mathrm{~mm} \mathrm{Hg}$, respectively). In olmesartan-treated patients, CBF significantly increased in the affected and unaffected hemispheres, and CRC increased significantly in the affected hemisphere. No increases in CBF and CRC were observed in amlodipine-treated patients. Patients treated with olmesartan showed effective rates of improvement in hand (30.0\%), upper extremities $(40.0 \%)$ and lower extremities $(100.0 \%)$, measured by Brunnstrom stage; these improvements were significantly different from those in amlodipine-treated patients for the total $(P<0.02)$ and lower extremity $(P<0.05)$ scores. There were no significant differences in Barthel indices and MiniMental State Examination (MMSE) scores. Olmesartan, but not amlodipine, had beneficial effects on CBF, CRC and rehabilitation outcomes in hypertensive stroke patients, by a mechanism independent of BP reduction and possibly by normalizing CBF autoregulation. Our results suggest that olmesartan may improve cerebral circulation and rehabilitation in hypertensive stroke patients in whom CBF autoregulation is impaired.

Hypertension Research (2009) 32, 1015-1021; doi:10.1038/hr.2009.143; published online 11 September 2009

Keywords: amlodipine; cerebral hemodynamics; olmesartan; rehabilitation outcome; stroke

\section{INTRODUCTION}

Hypertension is a major risk factor for stroke. ${ }^{1,2}$ In hypertensive patients, cerebral blood flow (CBF) is impaired, ${ }^{3}$ not only by elevated blood pressure (BP) but also as a result of inflammation and oxidative stress in the vascular wall, induced by angiotensin II., ${ }^{4,5}$ Angiotensin II receptor blockers (ARBs) and calcium channel blockers (CCBs) are widely used to treat hypertension. ARBs have been shown to reduce inflammation ${ }^{6}$ and oxidative stress ${ }^{7,8}$ by directly blocking the action of angiotensin II. Therefore, the effects on CBF of antihypertensive drugs that act as ARBs and CCBs may differ.

In healthy subjects, $\mathrm{CBF}$ is autoregulated to maintain a stable flow rate across a wide range of $\mathrm{BP}$ values, with a mean lower limit of $50-60 \mathrm{~mm} \mathrm{Hg}$. However, in patients with severe hypertension, CBF is affected when the mean BP drops below $100 \mathrm{~mm} \mathrm{Hg} .{ }^{9}$ Furthermore, in patients with cerebrovascular disease, $\mathrm{CBF}$ autoregulation can be disturbed, so that the mean BP necessary to maintain a constant CBF is higher than that in healthy subjects. ${ }^{10}$ This impaired autoregulation is thought to be largely a consequence of structural damage to small arteries in the brain, and is accompanied by a higher susceptibility to vasoactive substances.

From the effects of angiotensin II on vascular beds in organs such as the brain, interventions targeting the renin-angiotensin system were predicted to normalize the lowest BP at which CBF could be autoregulated in patients with an impaired cerebral circulation. The angiotensin-converting enzyme (ACE) inhibitor captopril was the first drug shown to maintain CBF while reducing BP below the lower limit for autoregulation in hypertensive rats. ${ }^{11,12}$ The ARB candesartan was subsequently reported to have similar effects. ${ }^{13}$ In 2005, Oku et al..$^{14}$ reported that the ARB losartan preserved $\mathrm{CBF}$ in hypertensive patients with a history of stroke, and effectively reduced their BP, thereby showing a successful shift in the lower limit of CBF autoregulation to a reduced BP level. These results led us to postulate that the direct blockade of angiotensin II receptors might reduce BP while maintaining an appropriate $\mathrm{CBF}$ in patients with impaired autoregulation. However, as ARBs are the most recent generation of antihypertensive drugs, few studies have yet investigated their effects on cerebral hemodynamics in humans. 
In this study, we compared the effects of the ARB olmesartan and the CCB amlodipine on cerebral hemodynamics in hypertensive patients with a history of stroke. We used ambulatory BP monitoring (ABPM) to measure BP, and xenon-computed tomography (Xe-CT) to measure $\mathrm{CBF}$ and cerebrovascular reserve capacity (CRC) in both the affected and unaffected hemispheres. Using this approach, we assessed the hemodynamic status of patients before and after olmesartan administration, using Xe-CT and an acetazolamide (ACZ) challenge test. ${ }^{15,16}$ We also evaluated rehabilitation outcomes.

\section{METHODS}

\section{Patients}

Inpatients of both genders, who were aged between 20 and 75 years and had hypertension and a history of first stroke, were eligible for participation in the study, provided that they satisfied the criteria described below during a pretreatment screening period of 2-7 days. Hypertensive patients were defined as those with systolic BP (SBP) $\geqslant 140$ and diastolic BP (DBP) $\geqslant 90 \mathrm{~mm} \mathrm{Hg}$ in clinic; the average $24 \mathrm{~h}$ ambulatory SBP during the screening period was $\geqslant 135 \mathrm{~mm} \mathrm{Hg}$, and the average $24 \mathrm{~h} \mathrm{DBP}$ was $\geqslant 85 \mathrm{~mm} \mathrm{Hg}$. Patients with chronic cerebrovascular disease were defined as those who had experienced an episode of supratentorial stroke more than 4 weeks earlier, defined by a cerebral infarction identified by X-ray, CT or MRI as well as neurological function.

The principal investigator judged the eligibility of the patients using these specific exclusion criteria: severe hypertension (SBP $\geqslant 180 \mathrm{~mm} \mathrm{Hg}$ or DBP $\geqslant 110 \mathrm{~mm} \mathrm{Hg}$ ); secondary hypertension; ongoing antihypertensive drug therapy that could not be discontinued; serum creatinine concentration $\geqslant 2.5 \mathrm{mg}$ per $100 \mathrm{ml}$; hypersensitivity to the test drug; pregnancy, the possibility of pregnancy, or lactation; severe hepatic disease; uncontrolled diabetes (with a $\left[\mathrm{HbA}_{1 \mathrm{c}}\right]$ level $>8 \%$ ); angina pectoris, myocardial infarction or heart failure; ongoing treatment with tranquilizers, histamine blockers or analgesics; severe aphasia that would impair the patient's ability to follow verbal instructions; dementia that would interfere with the outcome assessment; and stroke lesions in the bilateral hemispheres, brain stem or cerebellum.

In total, 35 patients ( 19 men and 16 women) with hemiplegia, who had been admitted to the Kirishima Rehabilitation Center, Kagoshima University, Japan, between January 2005 and May 2007, were enrolled in the study. Table 1 summarizes the baseline characteristics of these patients. The mean time

\section{Table 1 Baseline characteristics of the study patients}

\begin{tabular}{lcc}
\hline & $\begin{array}{c}\text { Olmesartan } \\
(\mathrm{n}=18)\end{array}$ & $\begin{array}{c}\text { Amlodipine } \\
(\mathrm{n}=17)\end{array}$ \\
\hline Age (years) & $60.8 \pm 10.2$ & $61.1 \pm 9.9$ \\
Sex (female/male) & $8 / 10$ & $8 / 9$ \\
Initiation of intervention from onset (weeks) & $10.8 \pm 9.7$ & $10.9 \pm 8.4$ \\
& & \\
CVD type & & 7 \\
ATBI & 3 & 7 \\
CE & 7 & $7 / 10$ \\
LAC & & \\
Side of hemiplegia (Rt/Lt) & $8 / 10$ & $153.6 \pm 10.9$ \\
Clinic BP (mm Hg) & & $96.1 \pm 10.3$ \\
Systolic BP & & \\
Diastolic BP & $95.3 \pm 12.3$ & \\
24- $h$ BP (mm Hg) & & $92.4 \pm 7.3$ \\
Systolic BP & & \\
Diastolic BP & & \\
\hline Abbreviations: ATBI, atherothrombotic brain infarction; BP, blood pressure; CE, cardioembolic \\
infarction; CVD, cerebrovascular disease; LAC, lacunar infarction; Lt, left; Rt, right.
\end{tabular}

between the occurrence of stroke and enrollment in the study was $10.8 \pm 9.0$ weeks with a range of 5-38 weeks. The baseline Brunnstrom stages were 3.4 for the hemiplegic hand (range 1-5), 3.5 for the upper extremities (range 2-6), and 4.0 for the lower extremities (range 2-6). Fifteen patients had right hemiplegia, and 20 had left hemiplegia.

\section{Study design}

This study adopted a prospective, double-blind and randomized controlled design. The number of subjects was calculated a priori. According to a metaanalysis, ${ }^{17}$ the minimal effect size for a therapy affecting motor recovery in stroke patients should be 0.54 . Therefore, a sample of 33 subjects was needed to achieve an $80 \%$ probability $(\beta=0.20)$ of detecting a $20 \%$ difference $(\alpha=0.05)$ between two treatment groups. To anticipate possible dropouts, we increased this number to 35 . After admission to the study, patients were randomly allocated to one of two treatment groups: olmesartan or amlodipine. Randomization was performed using a computer-generated random sequence of numbers provided by the Hospital's Informatics Departments. The randomization was conducted by one physician who was not involved with the inclusion or exclusion process.

For each patient, BP, CBF, CRC values and rehabilitation outcome measurements were collected during the screening period (baseline) and after 4 and 8 weeks' treatment. Patients were treated with either $10 \mathrm{mg}$ olmesartan medoxomil (Olmetec; Sankyo Pharmaceutical, Tokyo, Japan) once a day or $2.5 \mathrm{mg}$ amlodipine (Norvasc; Pfizer Japan, Tokyo, Japan) once a day for the first 4 weeks of the trial. The dose was increased over the next 4 weeks if a 24-h SBP/ DBP of $<135 / 85 \mathrm{~mm} \mathrm{Hg}$ was not achieved, or if reductions in the 24-h SBP/ DBP of $\geqslant 10 / 5 \mathrm{~mm} \mathrm{Hg}$ were not realized. The administration of other drugs that might influence the CBF (including statins, cilostazol and anti-convulsion medication) was prohibited during the study period. All of the subjects participated in a conventional stroke rehabilitation program five times per week, which consisted of range-of-motion exercises, muscle strengthening and basic activity training, gait and activities of daily living (ADL) training, and speech therapy.

The study protocol, which complied with the Declaration of Helsinki (1963, and revised in 1975 and 1983), was approved by the Ethics Committee of Kagoshima University, Japan, and conformed to the ethics guidelines of the hospital. Written informed consent for participation was obtained from all enrolled patients after they had been given a comprehensive explanation of the protocol, which included details of the irradiation dose used in the Xe-CT procedure.

\section{BP measurements}

BP was measured in clinic in the supine position, using a mercury sphygmomanometer with a 6-inch cuff. At enrollment and after 4 and 8 weeks' treatment, SBP and DBP (Korotkoff phases I and V, respectively) were calculated as the average of two readings taken $3 \mathrm{~min}$ apart. The 24-h BP was recorded using Type TM-Ultralite 90217 ABPM devices (Spacelabs Medical, Redmond, WA, USA) during the screening period, and at weeks 4 and 8 of treatment. Measurements were made every 30 min between 0700 and $2159 \mathrm{~h}$ and every $60 \mathrm{~min}$ between 2200 and $0659 \mathrm{~h}$. Symptoms, clinical findings and adverse events were monitored during the treatment period.

\section{CBF measurements}

$\mathrm{CBF}$ and $\mathrm{CRC}$ were measured by $\mathrm{Xe}-\mathrm{CT}^{15,16,18}$ during the screening period, and after 8 weeks' treatment. CBF was measured using the stable Xe-CT technique described by Gur et al. ${ }^{16}$ The patients lay still on the scanner bed, in a quiet, dimly lit room, with their eyes covered and inhaled $30 \%$ Xe gas, which is stable, radio-dense, lipid-soluble, and rapidly and freely diffuses across the bloodbrain barrier, for $4 \mathrm{~min}$. They then breathed normal air for $5 \mathrm{~min}$, exhaling into a trap. Regional CBF ( $\mathrm{rCBF}$ ) was measured by Xe-CT using high-sensitivity collimation and a computer to calculate the local Xe tissue-saturation curves according to Kety's formula. ${ }^{19}$ Serial CBF measurements were made at predesignated, standardized slices, passing through the basal ganglia, and including the midsection of the anterior horns of the lateral ventricles, caudate, putamen, thalamus and pineal body during the cerebral uptake phase of Xe gas. ${ }^{20}$ For the Xe-CT study, on the basis of earlier reports, regions of interest were selected 
around the bilateral hemispheres of both the affected and unaffected sides. ${ }^{4}$ Regions of interest (ROI) were defined with reference to Kretschmann and Weinrich's atlas. ${ }^{21}$

CRC, defined as the change in CBF 20 min after ACZ injection, ${ }^{18}$ was measured by taking two CBF measurements, at rest and $20 \mathrm{~min}$ after the intravenous administration of $1 \mathrm{~g} \mathrm{ACZ}{ }^{22}$ We also calculated the CBF response to ACZ, that is (CBFacz-CBFrest/CBFrest $\times 100 \%$ ) as the 'CRC (\%)'. The changes in $\mathrm{CBF}$ that occurred after administering $\mathrm{ACZ}$ were computed for each ROI. Quantification of rCBFs for each hemisphere was performed by manually outlining the areas on the display console. If an infarct was included within a standard ROI, the area was reduced to avoid this region. CBF images were transformed into standardized brain images using imaging software (AZ-7000W98; Anzai Medical, Tokyo, Japan).

\section{Rehabilitative outcome measures}

Three rehabilitation outcome instruments were used at baseline and after treatment: the Brunnstrom stage ${ }^{23}$ as a measure of hemiplegia, the Barthel index ${ }^{24,25}$ as an assessment tool for ADL, and the Mini-Mental State Examination (MMSE) $)^{26}$ as a measure of cognition.

\section{Statistical analysis}

All data were expressed as means \pm s.d. Baseline characteristics of the two study groups were compared using an unpaired $t$-test and StatMate III software (ATMS, Tokyo, Japan). Within the groups, baseline and post-treatment data were analyzed using the paired sample $t$-test. BP, CBF and CRC measurements were analyzed by 2 -way analysis of variance (ANOVA) with repeated measures and Scheffe's test for significant interactions.

Improvements in motor function measured by the Brunnstrom stage were expressed as an effective rate (ER). The number of effective parts was defined as the number of each part (hand or upper limb or lower limb), in which the Brunnstrom stage improved from below stage 3 to above stage 3. The total number was the number of all effective parts and the number of parts in which the Brunnstrom stage of motor function was lower than stage 3 . ER=number of effective motor parts/total number $\times 100 \%$. The $\chi^{2}$-test was used to analyze differences in ER between the two study groups.

Barthel indices and MMSE scores before and after treatment were analyzed using the Wilcoxon signed-ranks test and the Mann-Whitney $U$-test. $P$-values $<0.05$ were considered statistically significant.

\section{RESULTS}

\section{Patients' clinical characteristics}

The baseline clinical characteristics of the two treatment groups are shown in Table 1. The two groups were similar with respect to age, sex, initiation of intervention from onset, cerebrovascular disease type, side of hemiplegia, clinic BP and 24-h BP.

All patients complied with treatment and completed the trial. Olmesartan and amlodipine were well tolerated by all patients, and no complications or adverse events (severe or fatal) occurred during the 8 -week treatment period. The final olmesartan dose required to control BP was $10 \mathrm{mg} \mathrm{day}^{-1}$ in nine patients and $20 \mathrm{mg} \mathrm{day}^{-1}$ in nine patients. The final amlodipine dose required to control BP was $2.5 \mathrm{mg} \mathrm{day}^{-1}$ in eight patients and $5.0 \mathrm{mg} \mathrm{day}^{-1}$ in nine patients. All 35 patients underwent two ACZ challenges and the examination was well tolerated in all cases. The physiological BP measurements and rehabilitation outcome measurements were also completed safely in all subjects.

\section{BP}

Both olmesartan and amlodipine significantly reduced clinic BP after 4 and 8 weeks' treatment (Table 2). Similar reductions in SBP were seen in both groups after 4 weeks $(-13.2 \pm 6.2 \mathrm{~mm} \mathrm{Hg}$ vs. $-13.1 \pm 6.1 \mathrm{~mm} \mathrm{Hg}, P=0.937)$ and 8 weeks $(-19.4 \pm 8.7$ vs. $-19.2 \pm 8.0 \mathrm{~mm} \mathrm{Hg}, P=0.897)$. Reductions in DBP were also similar in the two groups after 4 weeks $(-10.9 \pm 5.3$ vs. $-10.8 \pm 5.2 \mathrm{~mm} \mathrm{Hg}$,
Table 2 Clinic blood pressure before and after the treatment

\begin{tabular}{lcc}
\hline & Olmesartan $(\mathrm{n}=18)$ & Amlodipine $(\mathrm{n}=17)$ \\
\hline$S B P$ & & \\
$\quad$ Baseline & $153.3 \pm 12.3$ & $153.6 \pm 10.9$ \\
After 4 weeks & $140.2 \pm 9.4^{*}$ & $140.5 \pm 10.2^{*}$ \\
$\quad P$-value (2-way ANOVA) & $P=0.937$ & \\
After 8 weeks & $133.9 \pm 6.5^{*}$ & $134.4 \pm 8.1^{*}$ \\
$\quad P$-value (2-way ANOVA) & $P=0.897$ & \\
& & \\
DBP & & \\
Before & $95.3 \pm 9.7$ & $85.1 \pm 10.3$ \\
After 4 weeks & $84.4 \pm 7.1^{*}$ & \\
$\quad P$-value (2-way ANOVA) & $P=0.768$ & \\
After 8 weeks & $81.9 \pm 7.1^{*}$ & \\
$P$-value (2-way ANOVA) & $P=0.768$ & \\
\hline A & &
\end{tabular}

Abbreviations: ANOVA, analysis of variance; DBP, diastolic blood pressure; SBP, systolic blood

pressure.
${ }^{*} P<0.01$ vs. baseline by paired $t$-test.

$P=0.768)$ and 8 weeks $(-13.4 \pm 5.7$ vs. $-13.4 \pm 7.3 \mathrm{~mm} \mathrm{Hg}, P=0.768)$. There were no significant differences in the BP profiles over time between the two groups during treatment.

Figure 1 shows 24-h BP data measured by ABPM during treatment. The overall results were similar to those for clinic BP measurements, with both drugs showing a stable hypotensive effect over $24 \mathrm{~h}$. In addition, BP did not increase in either group within the $24 \mathrm{~h}$ period after the last drug dose was administered, indicating that the hypotensive effects of both drugs were persistent. Mean BP reductions were calculated for each $24 \mathrm{~h}$, daytime (0700-2159 hours) and nighttime (2200-0659 hours) period, adjusted for baseline, as shown in Table 3. The reduction in the mean 24-h DBP of $9.2 \mathrm{~mm} \mathrm{Hg}$ seen with olmesartan was not significantly different from the reduction of $8.6 \mathrm{~mm} \mathrm{Hg}$ obtained with amlodipine. There were no significant differences between the two groups (Table 3 ).

\section{CBF}

Figure 2 shows CBF values for the affected and unaffected hemispheres at baseline and after 8 weeks' treatment with olmesartan or amlodipine. CBF increased in both sides of the brain after treatment with olmesartan, but did not change significantly in either side in the amlodipine group. In the olmesartan group, the mean CBF increased by $15.5 \%$ (from $34.2 \pm 4.2$ to $39.5 \pm 4.5 \mathrm{ml} / \mathrm{min} / 100 \mathrm{~g} ; P<0.01$ ) in the affected hemisphere, and by $9.2 \%$ (from $43.5 \pm 5.6$ to $47.6 \pm 5.9 \mathrm{ml} /$ $\mathrm{min} / 100 \mathrm{~g} ; P<0.01)$ in the unaffected hemisphere. In the amlodipine group, the mean $\mathrm{CBF}$ did not increase significantly in either the affected (from $34.3 \pm 4.5$ to $34.7 \pm 4.2 \mathrm{ml} / \mathrm{min} / 100 \mathrm{~g}$, not significant) or unaffected hemispheres (from $42.7 \pm 5.8$ to $42.6 \pm 4.1 \mathrm{ml} / \mathrm{min} /$ $100 \mathrm{~g}$, not significant).

The increase in $\mathrm{CBF}$ was significantly greater in patients treated with olmesartan compared with patients treated with amlodipine, in both the affected $(P<0.001)$ and unaffected $(P<0.001)$ hemispheres, assessed by 2-way ANOVA with repeated measures.

CRC

Figure 3 shows the CRC values for the affected and unaffected hemispheres at baseline, and after 8 weeks' treatment with olmesartan or amlodipine. CRC was significantly increased in the olmesartan group but not in the amlodipine group. In patients treated with olmesartan, the mean CRC in the affected hemisphere showed a 
Olmesartan $(n=18)$
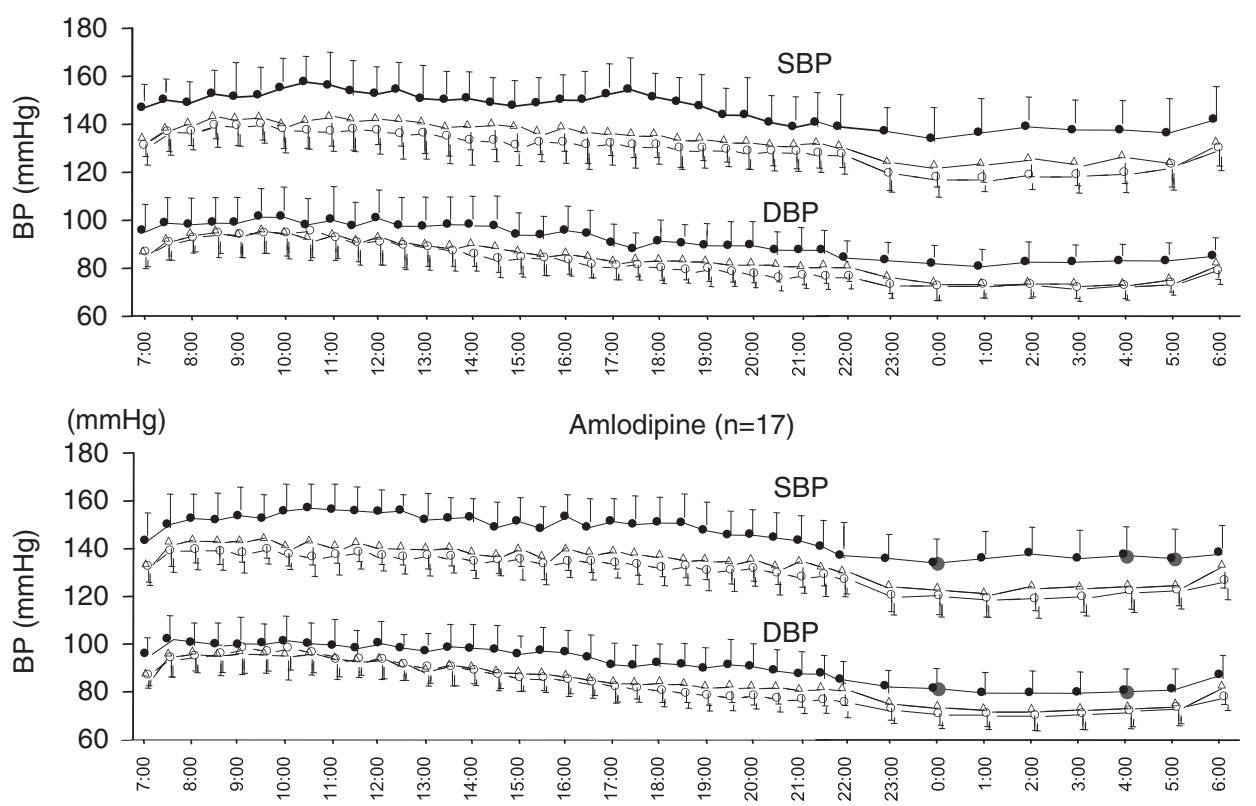

Figure 1 Mean hourly systolic blood pressure (SBP) and diastolic blood pressure (DBP) from ambulatory BP monitoring before $(\bullet)$ and after $4(\Delta)$ and $8(O)$ weeks' treatment with olmesartan or amlodipine. SBP, systolic blood pressure; DBP, diastolic blood presure.

Table 3 Changes in blood pressure after 4 and 8 weeks treatment with olmesartan or amlodipine

\begin{tabular}{lccc}
\hline & $\begin{array}{c}\text { Olmesartan } \\
(\mathrm{n}=18)\end{array}$ & $\begin{array}{c}\text { Amlodipine } \\
(\mathrm{n}=17)\end{array}$ & P-value \\
\hline 4 weeks & & & \\
24-h average $\Delta \mathrm{SBP}$ & $-12.0 \pm 1.7$ & $-11.9 \pm 1.7$ & 0.8330 \\
Daytime average $\Delta \mathrm{SBP}$ & $-12.1 \pm 2.1$ & $-12.1 \pm 2.1$ & 0.9702 \\
Nighttime average $\Delta \mathrm{SBP}$ & $-11.9 \pm 5.5$ & $-11.2 \pm 2.8$ & 0.6500 \\
24-h average $\Delta \mathrm{DBP}$ & $-7.1 \pm 0.7$ & $-6.9 \pm 1.0$ & 0.6934 \\
Daytime average $4 \mathrm{DBP}$ & $-7.0 \pm 1.1$ & $-7.0 \pm 1.3$ & 0.9605 \\
Nighttime average $4 \mathrm{DBP}$ & $-7.2 \pm 3.2$ & $-6.6 \pm 3.0$ & 0.4254 \\
& & & \\
8 weeks & & & \\
24-h average $\Delta \mathrm{SBP}$ & $-16.1 \pm 2.7$ & $-15.7 \pm 3.1$ & 0.5572 \\
Daytime average $\Delta \mathrm{SBP}$ & $-16.0 \pm 3.1$ & $-16.0 \pm 3.6$ & 0.9205 \\
Nighttime average $\Delta \mathrm{SBP}$ & $-16.2 \pm 6.7$ & $-14.7 \pm 4.0$ & 0.6333 \\
24-h average $\Delta \mathrm{DBP}$ & $-9.2 \pm 2.9$ & $-8.6 \pm 3.3$ & 0.5876 \\
Daytime average $\Delta \mathrm{DBP}$ & $-9.2 \pm 3.2$ & $-8.5 \pm 3.4$ & 0.5514 \\
Nighttime average $\Delta \mathrm{DBP}$ & $-9.0 \pm 4.1$ & $-8.9 \pm 4.6$ & 0.9286 \\
\hline
\end{tabular}

Abbreviations: DBP, diastolic blood pressure; SBP, systolic blood pressure.

significant increase of $53.6 \%$ (from $8.4 \pm 4.3$ to $12.9 \pm 5.1 \mathrm{ml} / \mathrm{min} /$ $100 \mathrm{~g} ; P<0.01)$, but was unchanged in the unaffected hemisphere (from $11.5 \pm 5.6$ to $12.0 \pm 4.4 \mathrm{ml} / \mathrm{min} / 100 \mathrm{~g}$; not significant). Patients treated with amlodipine showed no significant changes in CRC in either hemisphere (affected, $8.3 \pm 3.9$ vs. $8.3 \pm 5.6 \mathrm{ml} / \mathrm{min} / 100 \mathrm{~g}$, not significant; unaffected, $11.1 \pm 5.5$ vs. $10.8 \pm 5.2 \mathrm{ml} / \mathrm{min} / 100 \mathrm{~g}$, not significant). The increase in CRC was significantly greater in the olmesartan group compared with the amlodipine group in the affected hemispheres $(P<0.001$ by 2 -way ANOVA with repeated measures), but not in the unaffected hemispheres $(P=0.5244)$.

In the olmesartan group, the CRC (\%) showed a significant increase from $19.8 \pm 8.0$ to $30.7 \pm 8.6 \%(P<0.01)$ in the affected hemisphere, but was unchanged $(32.1 \pm 11.0$ vs. $31.6 \pm 8.1 \%)$ in the unaffected hemisphere. In the amlodipine group, there was no significant change in the CRC (\%) in either the affected hemisphere $(20.8 \pm 9.3 \mathrm{vs}$. $21.0 \pm 13.7 \%$, not significant) or the unaffected hemisphere (30.7 \pm 14.5 vs. $30.1 \pm 13.7 \%$, not significant). The increase in the CRC (\%) was significantly greater in the olmesartan group than in the amlodipine group in the affected hemispheres $(P<0.01$ by 2 -way ANOVA with repeated measures), but not in the unaffected hemispheres $(P=0.7832)$.

\section{Rehabilitation outcome measures}

Table 4 shows the Brunnstrom stages for the olmesartan and amlodipine groups. In the olmesartan group, the ER for the hand was $30.0 \%$, with three patients improving their Brunnstrom stage from below 3 to above 3 . The ER was $40.0 \%$ for the upper extremities, with 4 out of 10 patients improving, and $100.0 \%$ for the lower extremities, with all six patients improving significantly $(P<0.05)$. The improvement in total ER for the olmesartan group was significant compared with that for the amlodipine group (Table $4, P<0.02$ ).

Barthel indices in both treatment groups improved significantly after 8 weeks $(P<0.05)$. In patients treated with olmesartan, the mean Barthel index rose from $56 \pm 28$ to $81 \pm 22$ and in patients treated with amlodipine, it rose from $54 \pm 26$ to $78 \pm 21$. However, there was no statistically significant difference between the two treatment groups (Table 5). Similarly, MMSE scores improved significantly in both groups, but there was no statistically significant difference between the two groups (Table 5).

\section{DISCUSSION}

This study has shown that treating hypertensive stroke patients for 8 weeks with olmesartan, but not amlodipine, increased CBF in the affected and unaffected hemispheres, increased CRC in the affected hemisphere, and improved rehabilitation outcomes, despite both drugs achieving comparable reductions in BP (Figures 2 and 3). 

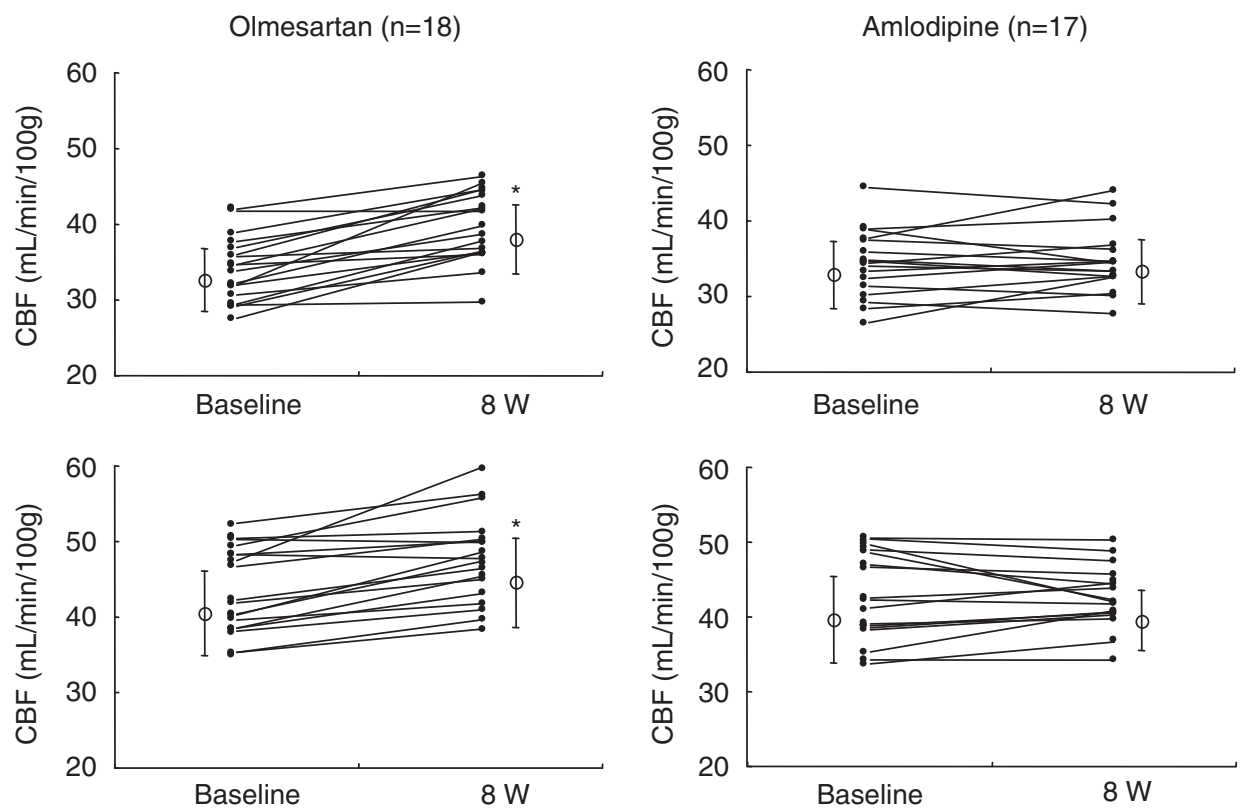

Figure 2 Cerebral blood flow (CBF) before and after treatment. Upper panels show CBF on the affected side of the brain and the lower panels show CBF on the unaffected side. Circles with bars represent means \pm s.d. Increases in CBF observed in both the affected and unaffected sides of the brain were statistically significant ( ${ }^{*} P<0.01$ vs. baseline) in the Olmesartan group.
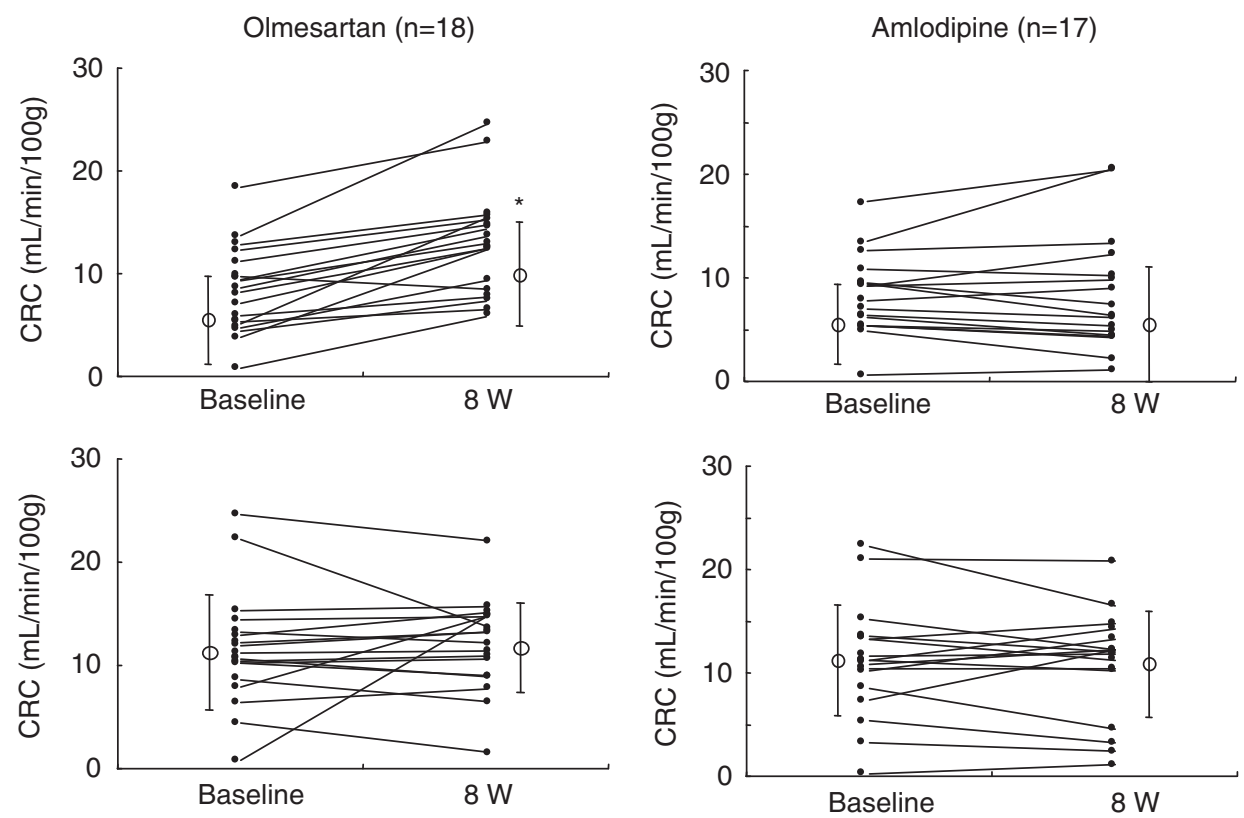

Figure 3 Cerebrovascular reserve capacity (CRC) before and after treatment. Circles with bars represent means \pm s.d. Only the increase in CRC observed on the affected side of the brain in the Olmesartan group was statistically significant $\left({ }^{*} P<0.01 \mathrm{vs}\right.$. baseline).

On the basis of the goal rate, BP was assessed using ABPM, which can accurately evaluate hypertension, the risk of cardiovascular events or stroke, and the efficiency of antihypertensive agents over 24-h dosing intervals. ABPM has shown that olmesartan has a strongly hypotensive effect, as a result of its double-chain domain, ${ }^{27,28}$ and, as suggested by earlier reports, ${ }^{29,30}$ might be significantly more effective than other ARBs. In this study, both SBP and DBP decreased significantly in all patients taking olmesartan and amlodipine. ABPM over $24 \mathrm{~h}$ showed that both drugs had a stable hypotensive effect lasting for at least $24 \mathrm{~h}$ after administration.
Hypertension is seen in the majority of patients who have suffered ischemic stroke, and a circadian pattern in the onset of stroke has been identified. Antihypertensive treatment currently focuses on controlling 24-h BP, but in the Jichi Morning Hypertension Research study $\left(\mathrm{J}_{\text {-MORE }}{ }^{31}\right.$ ) approximately $61 \%$ of patients on antihypertensive drugs still experienced early morning hypertension. This highlighted the need for better ARBs and CCBs, the principal antihypertensive agents used in Japan, with sustained action, to achieve ideal hypotensive effects. Both the sympathetic nervous system and the reninangiotensin system are thought to be involved in the elevation in early 
Table 4 Changes in Brunnstrom stage after treatment with olmesartan or amlodipine

\begin{tabular}{|c|c|c|c|c|c|c|c|c|}
\hline & \multicolumn{8}{|c|}{ Number of patients } \\
\hline & \multicolumn{2}{|c|}{ Hand } & \multicolumn{2}{|c|}{ Upper extremities } & \multicolumn{2}{|c|}{ Lower extremities } & \multicolumn{2}{|c|}{ Sum } \\
\hline & Olm & $A m l$ & Olm & $A m l$ & Olm & $A m l$ & Olm & $A m l$ \\
\hline \multicolumn{9}{|l|}{ Before treatment } \\
\hline$\leqslant$ Stage 3 & 10 & 9 & 10 & 8 & 6 & 6 & 26 & 23 \\
\hline$>$ Stage 3 & 8 & 8 & 8 & 9 & 12 & 11 & 28 & 28 \\
\hline \multicolumn{9}{|l|}{ After treatment } \\
\hline$\leqslant$ Stage 3 & 7 & 9 & 6 & 7 & 0 & 3 & 13 & 19 \\
\hline > Stage 3 & 11 & 8 & 12 & 10 & 18 & 14 & 41 & 32 \\
\hline Effective $^{a}$ & 3 & 0 & 4 & 1 & 6 & 3 & 13 & 4 \\
\hline Ineffective ${ }^{b}$ & 7 & 9 & 6 & 7 & 0 & 3 & 13 & 19 \\
\hline Effective rate (\%) & 30.0 & 0 & 40.0 & 12.5 & 100.0 & 50.0 & 50.0 & 17.4 \\
\hline$P$-value $\left(\chi^{2}\right.$-test $)$ & \multicolumn{2}{|c|}{0.0734} & \multicolumn{2}{|c|}{0.1955} & \multicolumn{2}{|c|}{$0.0455^{*}$} & \multicolumn{2}{|c|}{$0.0167^{*}$} \\
\hline
\end{tabular}

Abbreviations: Aml, amlodipine; Olm, olmesartan

The Brunnstrom stage changed from less than stage 3 to more than stage 3 after treatment. ${ }^{\mathrm{b}}$ The Brunnstrom stage was still less than stage 3 after treatment.

${ }^{*} P$-values $<0.05$ were considered statistically significant. Effective rates for patients in the olmesartan group improved significantly compared with those in the amlodipine group.

Table 5 Significant improvements in Barthel indices and MMSE scores before and after treatment

Olmesartan $(\mathrm{n}=18) \quad$ Amlodipine $(\mathrm{n}=17)$

\begin{tabular}{lcc}
\hline Barthel index & & \\
Before treatment & $56 \pm 28$ & $54 \pm 26$ \\
After treatment & $81 \pm 22^{*}$ & $78 \pm 21^{*}$ \\
Difference & $25.8 \pm 17.6$ & $24.1 \pm 15.7$ \\
$P$-value (Mann-Whitney's U-test) & $P=0.8173$ & \\
& & \\
$M M S E$ & & $25 \pm 3$ \\
Before treatment & $24 \pm 3$ & $27 \pm 2^{*}$ \\
After treatment & $28 \pm 3^{*}$ & $1.7 \pm 2.4$ \\
Difference & $3.2 \pm 2.1$ & \\
$P$-value (Mann-Whitney's U-test) & $P=0.1558$ &
\end{tabular}

Abbreviations: MMSE, Mini-Mental State Examination.

${ }^{*} P<0.05$ vs. baseline by Wilcoxon signed-ranks test.

morning BP, and therefore antihypertensive drugs that act on these systems might be valuable. In addition, a drug that can maintain BP control throughout a 24 -h period might be more effective in reducing cerebrovascular events. In this study, we have shown that olmesartan had a stable hypotensive effect lasting for at least $24 \mathrm{~h}$, which could control early morning BP, as shown in an earlier study (Figure 1, Table 3$)^{29}$.

Shimizu et al. ${ }^{32}$ showed earlier that amlodipine had no effect on cerebral blood flow in hypertensive patients with a history of ischemic stroke. Our results also suggested that ARBs, but not CCBs, might improve cerebral hemodynamics, which are highly susceptible to damaging cerebrovascular risk factors such as hypertension. Ogasawara et al. ${ }^{33}$ reported that reduced CBF and CRC were significantly associated with an increased risk of stroke recurring. Consequently, any treatment strategy that targets cerebral hemodynamics would be expected to prevent early episodes of cerebral ischemia by maintaining $\mathrm{CBF}$ and CRC. This study has provided direct evidence suggesting that ARBs have such beneficial effects on cerebral hemodynamics.
Furthermore, in the olmesartan group, our results also showed a significant positive correlation between the changes in the CBF and the following rehabilitation outcomes: the Brunnstrom stages of the upper limb $(r=0.39, P<0.05)$, the hand $(r=0.42, P<0.05)$ and the lower limb $(r=0.40, P<0.05)$. However, in the olmesartan group, there was no significant positive correlation between the changes in the $\mathrm{CBF}$ and the Barthel indices and MMSE scores. In addition, in the amlodipine group, there was no significant positive correlation between the changes in the $\mathrm{CBF}$ and the three rehabilitation outcome measurements.

However, the effects of ARBs on cerebral hemodynamics remain controversial. Other groups have reported similar effects for the ARB candesartan on cerebral hemodynamics. The beneficial influence of $\mathrm{AT}_{1}$ receptor inhibitors on CBF was supported by Nishimura et al. ${ }^{34}$ who showed that ARBs preserved $\mathrm{CBF}$ in spontaneously hypertensive rats with cerebral ischemia. Our results are consistent with these findings. However, Nishimura et al. ${ }^{34}$ compared the effects of ARBs with a placebo or propranolol, which restricts the interpretation possible for these data with respect to the effects on BP lowering. Furthermore, these earlier results were obtained in animal models, and few studies have evaluated the chronic effects of ARBs on cerebral hemodynamics in hypertensive patients. The beneficial effect of ARBs in hypertensive stroke patients may be explained by their chronic effects on the structure and function of vascular tissue. Blockade of angiotensin II AT1 receptors by olmesartan is thought to ameliorate damaged vascular structure and restore a physiologically normal tone in resistant arteries. In this way, the lower limit of autoregulation could be reset to a lower BP than that established as a consequence of stroke. However, these propositions require substantial further investigation in the future in both experimental and clinical studies.

To our knowledge, this is the first published investigation into the effects of ARBs showing a correlation between cerebral hemodynamics and rehabilitation outcomes in stroke patients. The goal of rehabilitative medicine is to restore patients to optimal function. The three rehabilitation outcome measures used in this study facilitated the interpretation of complex data, and allowed the clinician to perform cross-disease, cross-program and cross-population comparisons of function. We observed improvements in motor function in the hemiplegic hand, upper extremities and lower extremities (assessed by Brunnstrom stage), as well as in the ADL (assessed by the Barthel index) and cognitive function (assessed by the MMSE score) following treatment with olmesartan and amlodipine (Tables 4 and 5). In this study, improvement in the Brunnstrom stages, especially the ER for the lower extremities, was significantly greater in the olmesartan group compared with the amlodipine group. ADL scores improved significantly in both treatment groups and there was no statistically significant difference between them after treatment. We were surprised that the improvement in ADL scores in patients treated with olmesartan was not more significant. Hand function is known to make a very important contribution to the ADL measure. Table 4 shows that the ER for hand function in the olmesartan group was only $30.0 \%$, which was not significantly different from that in the amlodipine group. It is not clear whether the improvements seen were attributable to the intervention or occurred as an intrinsic part of the recovery after stroke. However, it is reasonable to expect that olmesartan treatment will improve cerebrovascular and neurological outcomes. ARBs may promote motor function, cognitive improvement and better ADL scores, thereby improving rehabilitation outcomes.

Advances in the measurement of CBF, by techniques such as $\mathrm{Xe}-\mathrm{CT}$ and single-photon emission CT and cerebral metabolism, by 
techniques such as positron emission tomography, have improved our assessment of cognitive function and functional changes in the brain. ${ }^{35}$ Statistically significant correlations have been reported between cognitive scores and CBF, particularly in stroke patients. ${ }^{36}$ This study did not directly address this point; however, parallel improvements in cognitive function and $\mathrm{CBF}$ would imply that increases in the latter would increase the supply of glucose and oxygen to brain neurons, which in turn would be expected to increase their activity and thus improve higher brain function. Treatment with olmesartan improved $\mathrm{CBF}$ and cognitive function, which was consistent with earlier reports. ${ }^{37}$ Ullman et al. ${ }^{38}$ reported that increases in $\mathrm{CBF}$ and CRC resulted in improved rehabilitation outcomes. We hypothesize that these improved rehabilitation outcomes might have resulted from reactivation of the $\mathrm{CBF}$ and CRC.

This study had some limitations. First, the sample size was small and a large-scale, multicenter, double-blinded study will be needed to confirm our results. Second, further studies will be needed to determine whether the results we have obtained with olmesartan can be generalized to all ARBs. Third, we did not optimize the doses of either olmesartan or amlodipine, and dose escalation studies will be needed to determine whether or not the effects seen are dose dependent.

In conclusion, our results confirmed that olmesartan is an effective antihypertensive drug that is well tolerated. Treating hypertensive patients with a history of stroke for 8 consecutive weeks with olmesartan decreased BP, and increased or preserved the blood flow and CRC in both the affected and unaffected sides of the brain. We suggest that the blockade of angiotensin II $\mathrm{AT}_{1}$ receptors by olmesartan is beneficial in these patients, because it preserves the autoregulation of CBF while hypotensive drugs are being administered and improves rehabilitation outcomes.

1 Kannel WB, Wolf PA, McGee DL, Dawber TR, McNamara P, Castelli WP. Systolic blood pressure, arterial rigidity, and risk of stroke. The Framingham study. JAMA 1981; 245: 1225-1229.

2 Tanaka H, Ueda Y, Hayashi M, Date C, Baba T, Yamashita H, Shoji H, Tanaka Y, Owada $\mathrm{K}$, Detels R. Risk factors for cerebral hemorrhage and cerebral infarction in a Japanese rural community. Stroke 1982; 13: 62-73.

3 Rudziñski W, Swiat M, Tomaszewski M, Krejza J. Cerebral hemodynamics and investigations of cerebral blood flow regulation. Nucl Med Rev Cent East Eur 2007; 10: 29-42.

4 Moriwaki H, Uno H, Nagakane Y, Hayashida K, Miyashita K, Naritomi H. Losartan, an angiotensin II $\left(\mathrm{AT}_{1}\right)$ receptor antagonist, preserves cerebral blood flow in hypertensive patients with a history of stoke. J Hum Hypertens 2004; 18: 693-699.

5 Ito T, Yamakawa H, Bregonzio C, Terrón JA, Falcón-Neri A, Saavedra JM. Protection against ischemia and improvement of cerebral blood flow in genetically hypertensive rats by chronic pretreatment with an angiotensin II AT1 antagonist. Stroke 2002; 33: 2297-2303

6 Fliser D, Buchholz K, Haller H. European Trial on Olmesartan and Pravastatin in Inflammation and Atherosclerosis (EUTOPIA) Investigators. Antiinflammatory effects of angiotensin II subtype 1 receptor blockade in hypertensive patients with microinflammation. Circulation 2004; 110: 1103-1107.

7 Kurata A, Nishizawa H, Kihara S, Maeda N, Sonoda M, Okada T, Ohashi K, Hibuse T, Fujita K, Yasui A, Hiuge A, Kumada M, Kuriyama H, Shimomura I, Funahashi T. Blockade of angiotensin II type-1 receptor reduces oxidative stress in adipose tissue and ameliorates adipocytokine dysregulation. Kidney Int 2006; 70: 1717-1724.

8 Tsuda M, Iwai M, Li JM, Li HS, Min LJ, Ide A, Okumura M, Suzuki J, Mogi M, Suzuki H, Horiuchi M. Inhibitory effects of AT1 receptor blocker, olmesartan, and estrogen on atherosclerosis via anti-oxidative stress. Hypertension 2005; 45: 545-551.

9 Strandgaard S, Olesen J, Skinhoj E, Lassen NA. Autoregulation of brain circulation in severe arterial hypertension. BMJ 1973; 1: 507-510.

10 Kuriyama Y, Sawada T, Omae T. Anitihypertensive drugs and cerebral circulation. In Omae T, Zanchetti A (eds), How should elderly hypertensive patients be treated? Springer: Tokyo, 1989, pp. 69-81.

11 Barry DI, Jarden JO, Paulson OB, Graham DI, Strandgaard S. Cerebrovascular aspects of converting-enzyme inhibition. I: effects of intravenous captopril in spontaneously hypertensive and normotensive rats. J Hypertens 1984; 2: 589-597.
12 Jarden JO, Barry DI, Juhler M, Graham DI, Strandgaard S, Paulson OB. Cerebrovascular aspects of converting-enzyme inhibition II: blood-brain barrier permeability and effect of intracerebroventricular administration of captopril. J Hypertens 1984; 2: 599-604.

13 Paulson OB, Jarden JO, Vorstrup S, Holm S, Godtfredsen J. Effect of captopril on the cerebral circulation in chronic heart failure. Eur J Clinical Invest 1986; 16: 124-132.

14 Oku N, Kitagawa K, Imaizumi M, Takasawa M, Piao R, Kimura Y, Kajimoto K, Matsumoto M, Hori M, Hatazawa J. Hemodynamic influences of losartan on the brain in hypertensive patients. Hypertens Res 2005; 28: 43-48.

15 Meyer JS, Shinohara T, Imai A, Kobari M, Sakai F, Hata T, Oravez WT, Timpe GM, Deville T, Solomon E. Imaging local cerebral blood flow by xenon-enhanced computed tomography: technical optimization procedures. Neuroradiology 1988; 30: 283-292.

16 Gur D, Yonas H, Good WF. Local cerebral blood flow by xenon-enhanced CT: current status, potential improvements, and future directions. Cerebrovasc Brain Metab Rev 1989; 1: 68-86.

17 Bolton DA, Cauraugh JH, Hausenblas HA. Electromyogram-triggered neuromuscular stimulation and stroke motor recovery of arm/hand functions: a meta-analysis. $J$ Neurol Sci 2004; 223: 121-127.

18 Nogami K, Fujii M, Kato S, Nishizaki T, Suzuki M, Yamashita S, Oda Y, Sadamitsu D, Maekawa T. Analysis of magnetic resonance imaging (MRI) morphometry and cerebral blood flow in patients with hypoxic-ischemic encephalopathy. J Clin Neurosci 2004; 11: $376-380$.

19 Kety SS. Theory and applications of the exchange of inert gas at the lungs and tissues. Pharmacol Rev 1951; 3: 5-48.

20 Okudaira Y, Nakanishi H, Arai H, Sato K. Differences in acetazolamide vasoreactivity in patients with acute and chronic occlusion of the internal carotid artery. J Clin Neurosc 2003; 10: 316-319.

21 Kretschmann HJ, Weinrich W. Neuroanatomy And Cranial Computed Tomography. Thieme: New York, 1986.

22 Pindzola RR, Balzer JR, Nemoto EM, Goldstein S, Yonas H. Cerebrovascular reserve in patients with carotid occlusive disease assessed by stable xenon-enhanced CT cerebral blood flow and transcranial Doppler. Stroke 2001; 32: 1811-1817.

23 Brunnstrom S. Movement Therapy In Hemiplegia: A Neurophysiological Approach. Harper \& Row: New York, 1970.

24 Mahoney F, Barthel D. Functional evaluation: the Barthel index. Md State Med J 1965; 14: 61 .

25 Song F, Jerosch-Herold C, Holland R, Drachler Mde L, Mares K, Harvey I. Statistical methods for analysing Barthel scores in trials of poststroke interventions: a review and computer simulations. Clin Rehabil 2006; 20: 347-356.

26 Folstein M. Mini-mental state: a practical method for grading the cognitive state of patients for the clinician. J Psychiatr Res 1975; 12: 189.

27 Miura S, Fujino M, Hanzawa H, Kiya Y, Imaizumi S, Matsuo Y, Tomita S, Uehara Y, Karnik SS, Yanagisawa H, Koike H, Komuro I, Saku K. Molecular mechanism underlying inverse agonist of angiotensin II type 1 receptor. J Biol Chem 2006; 281 : 19288-19295.

28 Miura S, Fujino M, Saku K. Angiotensin II receptor blocker as an inverse agonist: a current perspective. Curr Hypertens Rev 2005; 1: 115-121.

29 Smith DH, Dubiel R, Jones M. Use of 24-h ambulatory blood pressure monitoring to assess antihypertensive efficacy: a comparison of olmesartan medoxomil, losartan potassium, valsartan, and irbesartan. Am J Carsiovasc Drugs 2005; 5: 41-50.

30 Oparil S, Williams D, Chrysant SG, Marbury TC, Neutel J. Comparative efficacy of olmesartan, losartan, valsartan, and irbesartan in the control of essential hypertension. J Clin Hypertens 2001; 3: 283-291.

31 Ishikawa J, Kario K, Hoshide S, Eguchi K, Morinari M, Kaneda R, Umeda Y, Ishikawa S, Kuroda T, Hojo Y, Shimada K. J-MORE Study Group. Determinants of exaggerated difference in morning and evening blood pressure measured by self-measured blood pressure monitoring in medicated hypertensive patients Jichi Morning Hypertension Research (J-MORE) Study. Am J Hypertens 2005; 18: 958-965.

32 Shimizu $H$, Tominaga T, Fujiwara S. Amlodipine lowers blood pressure without significant effect on cerebral blood flow in hypertensive patients with a history of stroke: a quantitative single photon emission computed tomography study. J Stroke Cerebrovasc Dis 2003; 12: 266-270.

33 Ogasawara K, Ogawa A, Yoshimoto T. Cerebrovascular reactivity to acetazolamide and outcome in patients with symptomatic internal carotid or middle cerebral artery occlusion: a xenon-133 single-photon emission computed tomography study. Stroke 2002; 33: 1857-1862

34 Nishimura Y, Ito T, Saavedra JM. Angiotensin II AT 1 blockade normalizes cerebrovascular autoregulation and reduces cerebral ischemia in spontaneously hypertensive rats. Stroke 2000; 31: 2478-2486.

35 Howanitz EM, Wisotzek IE, Losonczy MF, Schaffer C. The relationship between menta status examination scores and cerebral blood flow in geriatric schizophrenia. Schizophr Res 2001; 49: 228-229.

36 Kitagawa Y, Meyer JS, Tachibana H, Mortel KF, Rogers RL. CT-CBF correlation of cognitive deficits in multi-infarct dementia. Stroke 1984; 15: 1000-1009.

37 Rogers RL, Meyer JS, Mortel KF, Mahurin RK, Judd BW. Decreased cerebral blood flow precedes multi-infarct dementia, but flows senile dementia of Alzheimer type. Neurology 1986; 36: 1-6.

38 Ullman JS, Bederson JB. Hypertensive, hypervolemic, hemodilutional therapy for aneurysmal subarachnoid hemorrhage. Is it efficacious? Yes. Crit Care Clin 1996; 12: 697-707. 